\title{
Induced in-source fragmentation pattern of certain novel $(1 Z, 2 E)-N$-(aryl)propanehydrazonoyl chlorides by electrospray mass spectrometry (ESI-MS/MS)
}

\author{
Ali S Abdelhameed*, Mohamed W Attwa, Hatem A Abdel-Aziz and Adnan A Kadi
}

\begin{abstract}
Background: Collision induced dissociation (CID) in the triple quadrupole mass spectrometer system (QQQ) typically yields more abundant fragment ions than those produced with resonance excitation in the presence of helium gas in the ion trap mass spectrometer system (IT). Detailed product ion spectra can be obtained from one stage $\mathrm{MS}^{2}$ scan using the QQQ. In contrast, generating the same number of fragment ions in the ion trap requires multiple stages of fragmentation $\left(\mathrm{MS}^{n}\right)$ using $\mathrm{CID}$ via in-trap resonance excitation with the associated time penalties and drop in sensitivity.
\end{abstract}

Results: The use of in-source fragmentation with electrospray ionization (ESI) followed by product ion scan $\left(\mathrm{MS}^{2}\right.$ ) in a triple quadrupole mass spectrometer system, was demonstrated. This process enhances the qualitative power of tandem mass spectrometry to simulate the $\mathrm{MS}^{3}$ of ion trap for a comprehensive study of fragmentation mechanisms. A five pharmacologically significant (1Z, 2E)- $N$-arylpropanehydrazonoyl chlorides (3a-e) were chosen as model compounds for this study. In this work, detailed fragmentation pathways were elucidated by further dissociation of each fragment ion in the ion spectrum, essentially, by incorporating fragmentor voltage induced dissociation (in-source fragmentation) and isolation of fragments in a quadrupole cell Q1. Subsequently, CID occurs in cell, Q2, and fragment ions are analyzed in Q3 operated in product ion mode this process can be referred to as pseudo-MS ${ }^{3}$ scan mode.

Conclusions: This approach allowed unambiguous assignment of all fragment ions using tandem mass spectrometer and provided adequate sensitivity and selectivity. It is beneficial for structure determination of unknown trace components. The data presented in this paper provide useful information on the effect of different substituents on the ionization/fragmentation processes and can be used in the characterization of this important class of compounds.

Keywords: In-source fragmentation, Hydrazones, Fragmentor voltage, Electrospray ionization

\section{Background}

Several types of ionization methods are available for use in mass spectrometry studies, such as electrospray ionization (ESI), matrix assisted laser desorption ionization (MALDI), chemical ionization $(\mathrm{CI})$, atmospheric pressure chemical ionization (APCI), or electron impact (EI). Electrospray ionization mass spectrometry (ESI-MS), as a powerful tool

\footnotetext{
* Correspondence: asaber@ksu.edu.sa

Department of Pharmaceutical Chemistry, College of Pharmacy, King Saud University, P.O. Box 2457, Riyadh 11451, Kingdom of Saudi Arabia
}

for the analysis, has been widely applied to the analysis of glycoproteins [1], oligonucleotides [2,3], oligosaccharides [4,5], drugs and drug metabolites [6], environmental contaminants $[7,8]$, and numerous other types of compounds [9]. In atmospheric pressure ion sources, e.g. APCI or electrospray ionisation (ESI), fragmentation of ions can occur in the ion source (in-source fragmentation) before ions reach the analyzer. In spite of the fact that this method of in source fragmentation is less selective than tandem mass spectrometry, as all ions in the source will be fragmented
() ChemistryCentral

(c) 2013 Abdelhameed et al.; licensee Chemistry Central Ltd. This is an Open Access article distributed under the terms of the Creative Commons Attribution License (http://creativecommons.org/licenses/by/2.0), which permits unrestricted use, distribution, and reproduction in any medium, provided the original work is properly cited. 
simultaneously, it has been used by several research groups [10-19]. On the other hand, collision induced dissociation (CID) in the triple quadrupole mass spectrometer system (QQQ) typically yields more abundant fragment ions than those produced with resonance excitation in the presence of helium gas in the ion trap (IT) [20]. Detailed product ion spectra can be obtained from one stage $\mathrm{MS}^{2}$ scan using the QQQ. In contrast, generating the same number of fragment ions in the ion trap requires multiple stages of fragmentation $\left(\mathrm{MS}^{\mathrm{n}}\right)$ using CID via in-trap resonance excitation with the associated time penalties and drop in sensitivity. Another drawback to the IT is the low mass cut-off in product ion scans. This arises from the fact that the precursor ion and the lowest $m / z$ fragment ion must be stable simultaneously in the IT $[20,21]$. In the present study, we combine the usage of in-source fragmentation with product ion scan $\left(\mathrm{MS}^{2}\right)$ to obtain structural information of certain novel $(1 Z, 2 E)-N$-(aryl)propanehydrazonoyl chlorides using electrospray ionization tandem mass spectrometry (ESI-MS/MS). The use of this approach was designed to improve the structure elucidation power of tandem mass spectrometry to simulate the $\mathrm{MS}^{3}$ of ion trap overcoming the aforementioned drawbacks of the latter.

Hydrazones have been reported as useful antiviral agents. Some acetylhydrazones revealed a remarkable antiviral activity against HSV-1 [22], whereas arylhydrazones inhibited the replication of HIV-1 [23]. Recently, Abdel-Aziz et al. reported the synthesis of a new class of $(1 Z, 2 E)-N$-(aryl)propanehydrazonoyl chlorides as analogs of compounds 3a-e (Scheme 1) [24,25] the structure and absolute configuration of this new class of hydrazonoyl chlorides were confirmed using X-ray analyses [25]. Furthermore, these derivatives were also used in economical and versatile synthetic approach for stereoselective synthesis of novel amidrazone derivatives with significant antifungal [25], and antiviral [24] potencies. Additionally, they can be considered very promising in the perspective of new drugs discovery. Amidrazones were also found to possess interesting biological activities [26-29]. Some of amidrazone-containing hetererocycles have demonstrated potent activity in vitro as antimicrobial agents. Amidrazone-substructural fragments were found to be the antifungal pharmacophore of the latter compounds [30-32]. Amidrazones have also been reported as precursors of some effective antifungal azoles [33]. Consequently, the efficient construction of these molecules has received significant attention [34-38]. Accordingly, in the light of interesting structural and biological results the situation definitely urges for some additional research in their analyses.

\section{Results and discussion Chemistry}

General procedure for the synthesis of $(1 Z, 2 E)$-2- (benzoyl/ benzothiazol-2-oyl)-N-arylpropanehydrazonoyl chlorides 3a-e. A mixture of benzoyl hydrazine 1a or benzothiazole2-carbohydrazide $1 \mathrm{~b}(10 \mathrm{mmol})$ and 2-oxo- $\mathrm{N}$-arylpropanehydrazonoyl chloride $\mathbf{2 a - d}(10 \mathrm{mmol})$ in absolute ethanol $(50 \mathrm{~mL})$ was refluxed for $9 \mathrm{~h}$. Then left to cool, the formed solid was filtered off, washed with ethanol, and recrystallized from EtOH/DMF to afford the corresponding hydrazonoyl chlorides $\mathbf{3 a}-\mathbf{e}$, respectively. The target compounds were synthesized via reacting 4-methylbenzohydrazide (1) with 2-oxo- $N$-arylpropanehydrazonoyl chlorides 2a-e in refluxing ethanol. The latter reaction produced, in each case, a single yellow product was identified as $(1 Z, 2 E)-2$ (2-(4-methylbenzoyl)hydrazono)- $N$-arylpropanehydrazonoyl chloride 3a-e.

\section{Mass spectrometry}

A preliminary MS2 scan followed by a product ion scan of each compound was carried out to determine the parent ion peaks as well as the fragment ions of compounds 3a-e. The data obtained played a guidance role prior to the pseudo- $\mathrm{MS}^{3}$ process for the same compounds. The highly sensitive product ion spectra of compounds 3a-e

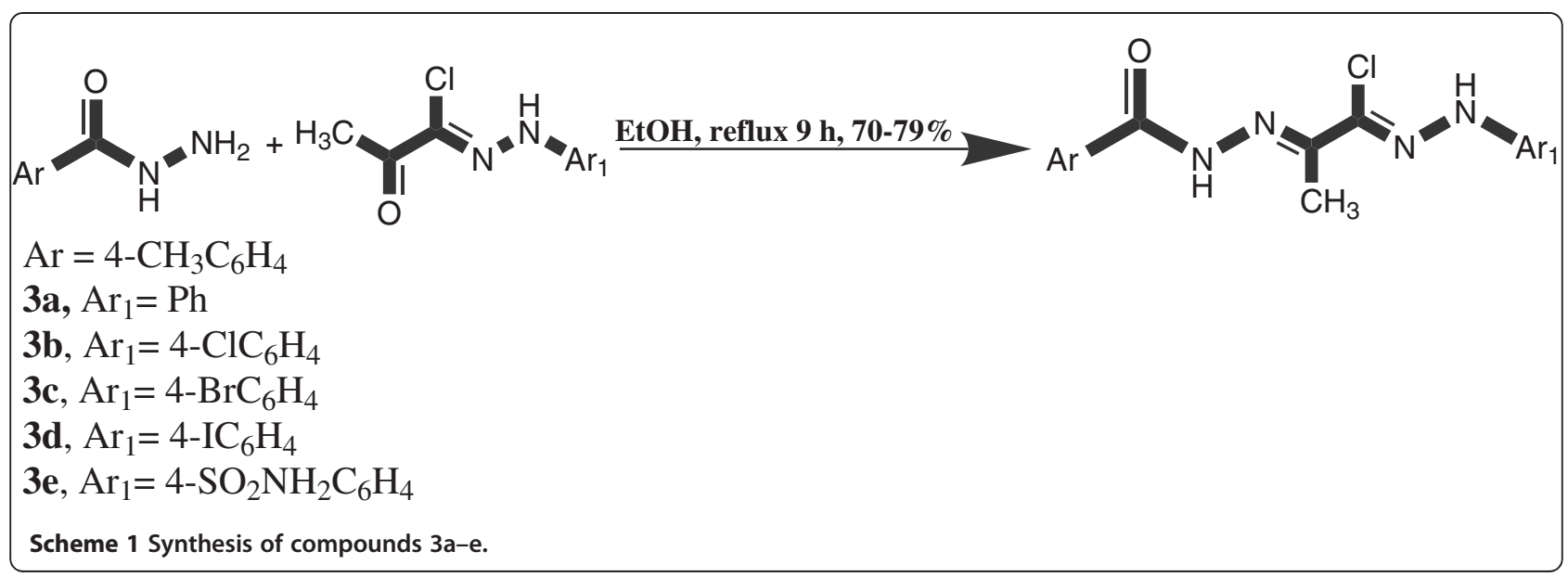



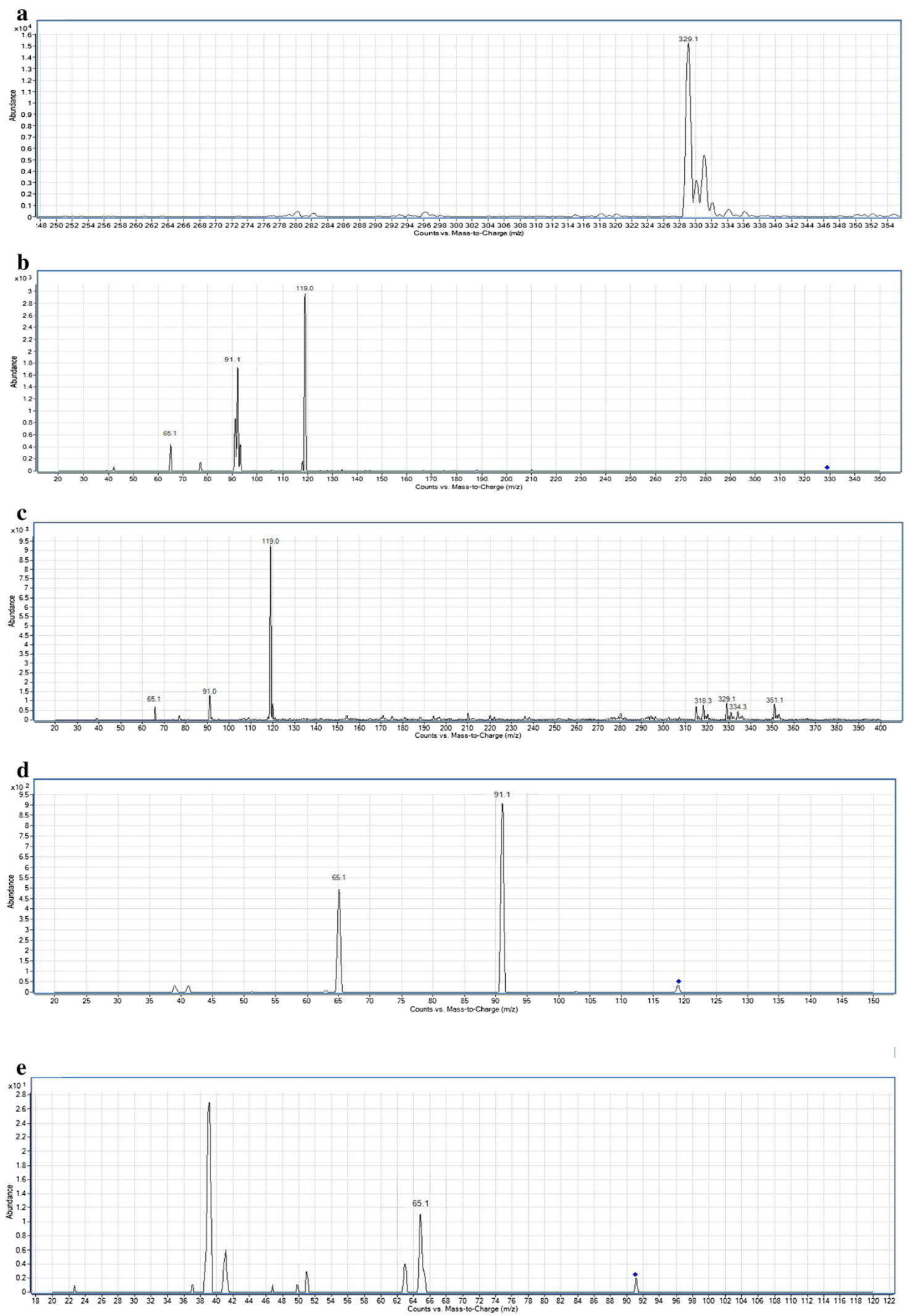

Figure 1 a) ESI mass spectrum of compound $3 \mathbf{a}[\mathbf{M}+\mathbf{H}]^{+}$ion $\left(\mathrm{m} / \mathbf{z}\right.$ 328.80). b) $\mathrm{MS}^{2}$ spectrum of $\mathrm{m} / \mathrm{z} 328.80$. c) In-source fragmentation of compound 3a. d) $M S^{2}$ spectrum of $\mathrm{m} / \mathrm{z}$ 119.14. e) $M S^{2}$ spectrum of $\mathrm{m} / \mathrm{z} 91.13$. 

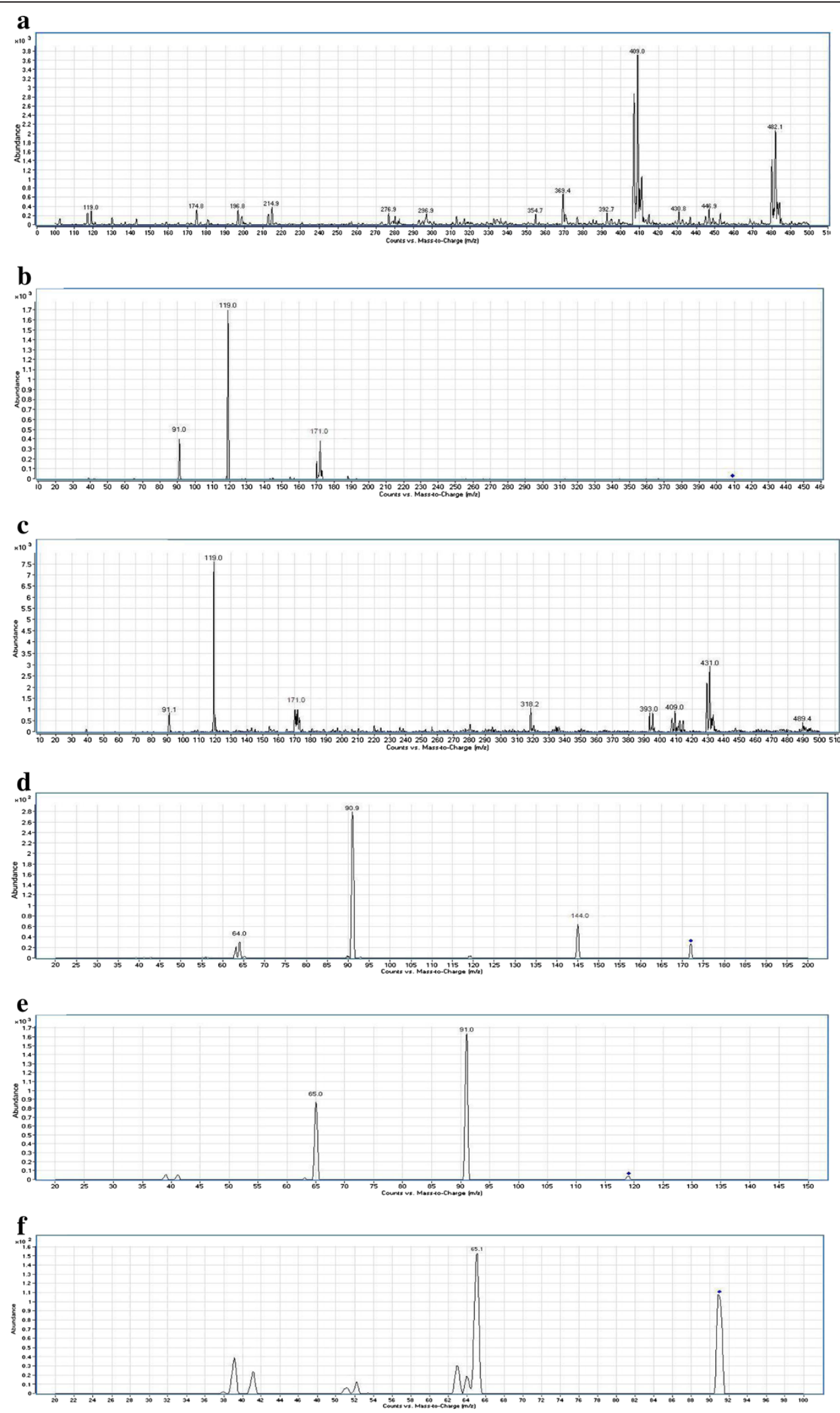

Figure 2 a) ESI mass spectrum of compound $3 c[M+H]^{+}$ion (m/z 409). b) $M S^{2}$ spectrum of $m / z$ 409. c) In-source fragmentation of compound 3c. d) $\mathrm{MS}^{2}$ spectrum of $\mathrm{m} / \mathrm{z}$ 171.01. e) $\mathrm{MS}^{2}$ spectrum of $\mathrm{m} / \mathrm{z} 119.14$. f) $\mathrm{MS}^{2}$ spectrum of $\mathrm{m} / \mathrm{z} 91.13$. 
obtained from a single-stage $\mathrm{MS}^{2}$ scan with abundant product ions and no low mass cut-off, are represented in Figures 1 and 2.

The fragmentation pathways of compounds 3a-e were investigated (Scheme 1). Introduction of different substituents to the investigated compounds showed marked effect on their ionization/fragmentation pattern. In-source fragmentation of $(1 Z, 2 E)$ - $N$-arylpropanehydrazonoyl chlorides that have an electron donating substituent on ring $\mathrm{B}$ $\left(\mathrm{X}=\mathrm{H}\right.$ or $\left.\mathrm{SO}_{2} \mathrm{NH}_{2}\right)$ showed limited fragmentation at the $\mathrm{N} /-\mathrm{C}=\mathrm{O}$ and $\mathrm{Ar} /-\mathrm{C}=\mathrm{O}$ bonds, with increased stability of the substituted ring $B$. This fragmentation mechanism produced three ion peaks with $\mathrm{m} / \mathrm{z}$ 65.09, 91.13 and 119.14, $\mathrm{MS}^{2}$ scan of the last two fragment ions produced $\mathrm{m} / \mathrm{z} 65.09$ and 91.13 with 65.09 respectively. Whereas, presence of an electron withdrawing substituent $(\mathrm{Cl}, \mathrm{Br}$ or I) on ring $\mathrm{B}$, produces similar fragmention mechanism in addition to yielding another pattern with dissociation occurs at the $\mathrm{N}$ $\mathrm{N}$ bond linked to the substituted ring $\mathrm{B}$ producing a protonated fragment with $\mathrm{m} / \mathrm{z} 126.56$ or 171.01 or 218.02 for $\mathrm{Cl}$ or $\mathrm{Br}$ or I, respectively. $\mathrm{MS}^{2}$ scan of this fragment ion shows three ion peaks m/z 91.13, 65.09 and 99.54 or 143.99

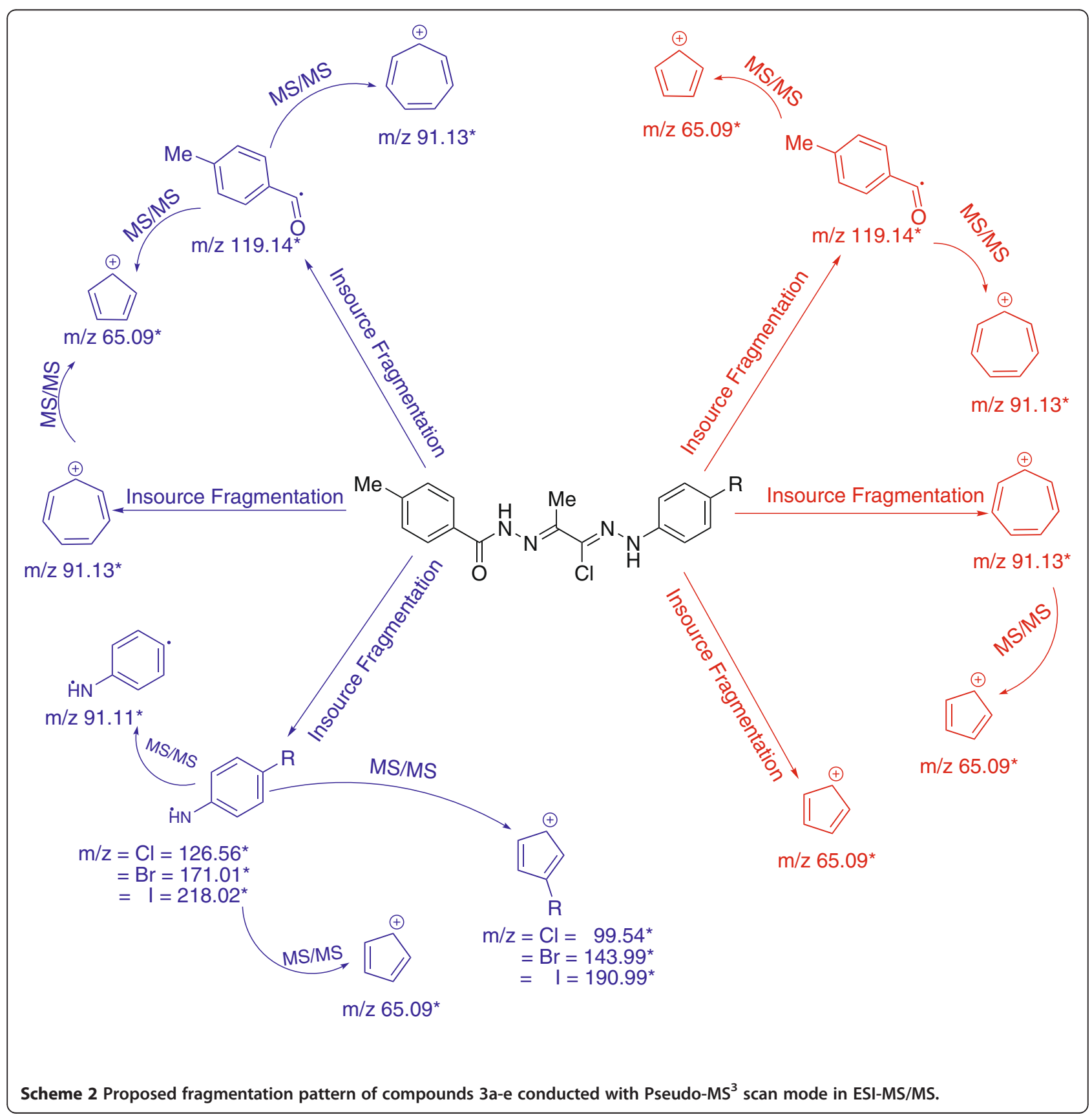


Table 1 Multistage MS data of compounds 3a-e by ESIMS/MS

\begin{tabular}{|c|c|c|c|c|c|}
\hline \multicolumn{6}{|c|}{ Product ions of protonated compounds $3 a-e[M+H]^{+}(m / z)$} \\
\hline & $\begin{array}{l}3 a \\
(328.80)\end{array}$ & $\begin{array}{l}3 b \\
(363.24)\end{array}$ & $\begin{array}{l}3 c \\
(409.0)\end{array}$ & $\begin{array}{l}3 d \\
(454.69)\end{array}$ & $\begin{array}{l}3 \mathrm{e} \\
(407.87)\end{array}$ \\
\hline \multirow{6}{*}{$\begin{array}{l}\text { In-source } \\
\text { fragmentation }\end{array}$} & 65.09 & & & & 65.09 \\
\hline & 91.13 & 91.13 & 91.13 & 91.13 & 91.13 \\
\hline & 119.14 & 119.14 & 119.14 & 119.14 & 119.14 \\
\hline & & 126.56 & & & \\
\hline & & & 171.0 & & \\
\hline & & & & 218.02 & \\
\hline \multirow[t]{4}{*}{ Product ion } & 65.09 & 65.09 & 65.09 & 65.09 & 65.09 \\
\hline & 91.13 & 91.13 & 91.13 & 91.13 & 91.13 \\
\hline & & 99.54 & & & \\
\hline & & & 143.99 & & \\
\hline
\end{tabular}

190.99

or 190.99 for $\mathrm{Cl}$ or $\mathrm{Br}$ or I, respectively. Ion peaks together with their corresponding proposed structures obtained from in-source fragmentation and $\mathrm{MS}^{2}$ scans for compound 3a-e are shown in Scheme 2 and are also summarized in Table 1.

\section{Experimental}

General method for synthesis of $(1 Z, 2 E)-2-(2-(4-$ methylbenzoyl)hydrazono)- $\mathrm{N}^{\prime}$-(aryl)propanehydrazonoyl chloride 3a-e

Unless otherwise indicated, all chemicals were purchased from Sigma (St. Louis, MO). To a solution of hydrazide $1(0.15 \mathrm{~g}, 1 \mathrm{mmol})$ in ethanol $(30 \mathrm{~mL})$, the appropriate propanehydrazonoyl chloride $2(1 \mathrm{mmol})$ was added. The reaction mixture was heated under refluxing temperature for $6 \mathrm{~h}$, then left to cool at room temperature. The precipitated product was filtered off, washed with ethanol and recrystallized from $\mathrm{EtOH} / \mathrm{DMF}$ to produce the corresponding $(1 Z, 2 E)$ $N$-arylpropanehydrazonoyl chlorides $3 \mathbf{a}-\mathbf{e}$ in $75-85 \%$ yield. The structures of all new compounds are shown in Figure 3.

\section{Mass spectrometry}

Reagents and solvents

HPLC grade water was obtained by Milli-Q connected to Elix Millipore water purification system (Millipore, USA). Acetonitrile (ACN) HPLC grade was purchased from BDH laboratory supplies (Poole-UK).

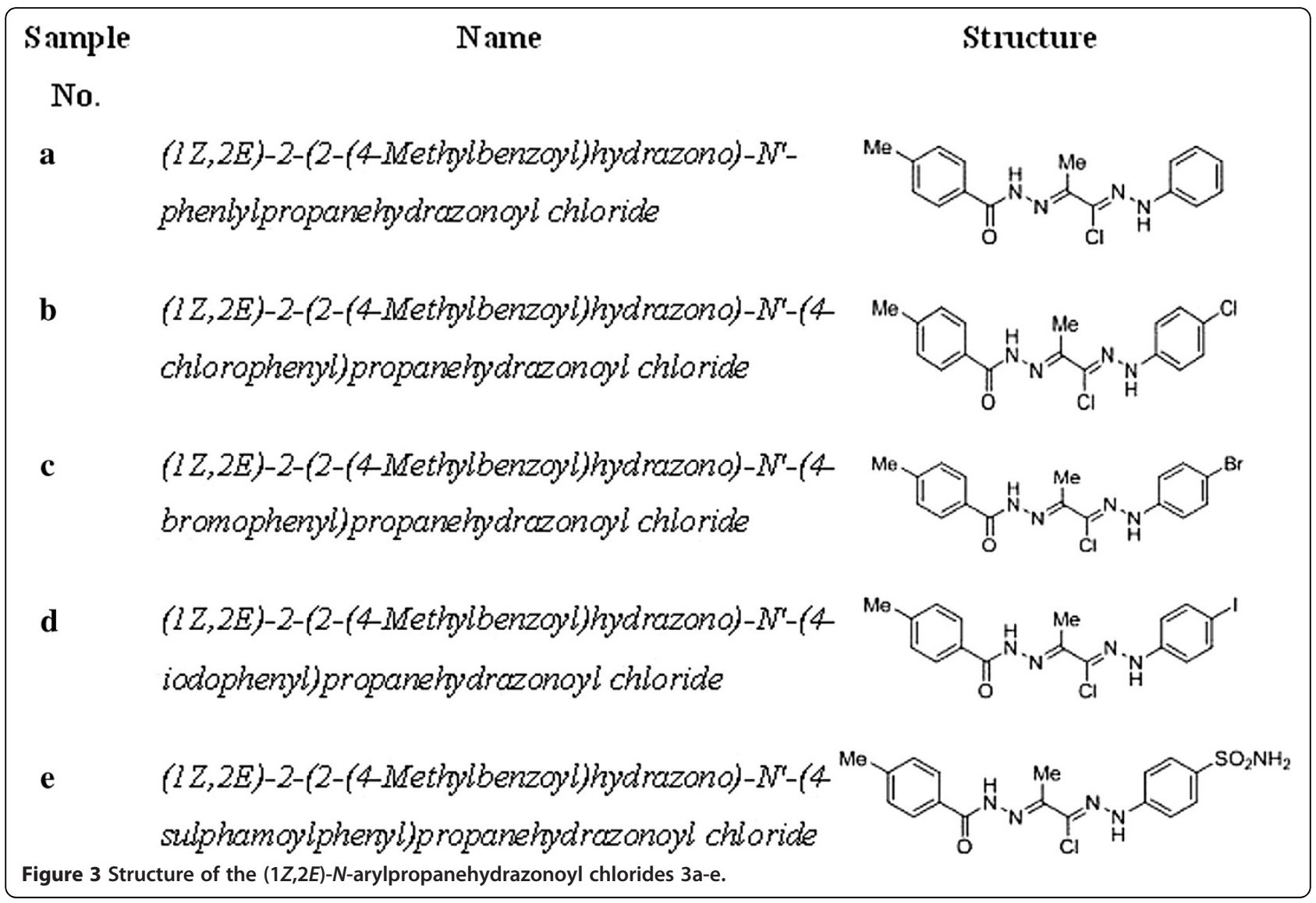




\section{LC-MS/MS}

An Agilent 6410 triple quadrupole mass spectrometer (Agilent technologies, USA) equipped with an electrospray ionization interface (ESI) coupled to an Agilent 1200 HPLC (Agilent Technologies, USA) was used. Agilent 1200 series system consists of G1311A binary pump, G1322A degasser, G1367B HIP-ALS autosampler, and G1316A thermostatted column compartment. A connector is used instead of the column to allow direct injection of samples. Mobile phase composed of two solvents: A is HPLC grade water, and B is acetonitrile mixed in the ratio 1:1. Compounds were prepared by weighing the solid substances to $1 \mathrm{mg} \cdot \mathrm{mL}^{-1}$ in ACN. Test solutions for MS were prepared by diluting the stock solutions with $\mathrm{ACN} / \mathrm{H} 2 \mathrm{O}$ mixture (1:1). Flow rate is $0.4 \mathrm{ml} / \mathrm{min}$, run time was 3 minutes. $10 \mu \mathrm{l}$ of each sample was injected into the LC-MS/MS. MS parameters were optimized for each compound by varying fragmentor voltage of the ion source for scan mode and collision energy for product ion mode. For optimization of the ionization conditions and of fragment ion spectra, analytes concentrations of 20 to $50 \mu \mathrm{g} \cdot \mathrm{mL}^{-1}$-depending on the ions intensities- were employed. For screening of mass signals of the different compounds and to search for parent ions for MS/MS experiments, MS2 scans were performed in the mass range of $\mathrm{m} / \mathrm{z} 100-600$. Because of the flow rate dependency of the ESI process, ion source specific parameters were readjusted. The ESI was operated in positive mode. The source temperature was set to $350^{\circ} \mathrm{C}$ and ion spray voltage was $4.5 \mathrm{kV}$.

To overcome the reduced selectivity problem of insource fragmentation, a product ion scan was performed prior to the in-source fragmentation to determine each compound's related fragment ions. The fragmentor voltage was optimized to produce adequate in-source fragmentation; values of $100,120,140,160,180$ and $200 \mathrm{~V}$ were tested to obtain the fragments of each compound in the scan spectra. The optimum fragmentor voltage to generate in-source fragments was $200 \mathrm{~V}$. Furthermore, the collision energy used for product ion $\left(\mathrm{MS}^{2}\right)$ analysis was also optimized by varying collision energy values $(4,6,8$, $10,12,14,16,18$ and $20 \mathrm{eV}$ ) and was set to $20 \mathrm{eV}$ to attain the fragment ions.

\section{Conclusions}

Mass spectrometry has shown to be an effective tool for the structural characterization of the synthesized compounds 3a-e. This work demonstrated a comprehensive fragmentation mechanism study of compounds 3a-e using the combination of induced in-source fragmentation with product ion scan $\left(\mathrm{MS}^{2}\right)$. The highly sensitive product ion spectra of compounds 3a-e were obtained from a single-stage $\mathrm{MS}^{2}$ scan with abundant product ions and no low mass cut-off. The detailed fragmentation pathways of all ions observed in the in-source fragmentation spectrum of compounds 3a-e were elucidated by further dissociation of each of these fragment ions using the product ion $\left(\mathrm{MS}^{2}\right)$ scan mode. The substructures of all fragment ions were unambiguously assigned. The approach described here is simple, sensitive, rapid and powerful for the identification of unknown compounds. Additionally, it can be used to identify trace amounts of metabolites and can be potentially applied to the analysis of impurities and degradation products in complex systems.

\section{Abbreviations}

CID: Collision induced dissociation; QQQ: Triple quadrupole mass spectrometer system; IT: Ion trap mass spectrometer system; MS ${ }^{n}$ : Multiple stages of fragmentation; ESI: Electrospray ionization; MALDI: Matrix assisted laser desorption ionization; APCl: Atmospheric pressure chemical ionization; Cl: Chemical ionization; ESI-MS: Electrospray ionization mass spectrometry; El: Electron impact; ACN: Acetonitrile; HPLC: High-performance liquid chromatography.

\section{Competing interests}

The authors declare that they have no conflict of interests.

\section{Authors' contributions}

ASA proposed the subject, designed the study, and wrote the draft version of the manuscript. MA conducted the mass spectrometric analysis of the compounds. HA conducted the synthesis of the investigated compounds and wrote the chemistry part of the manuscript. AK participated in study design, literature review, mass spectrometric analysis and preparation of the manuscript. All authors read and approved the final manuscript.

\section{Acknowledgments}

Authors would like to thank the Deanship of Scientific Research and the Research Center of the College of Pharmacy, King Saud University for supporting this study.

Received: 11 November 2012 Accepted: 23 January 2013

Published: 25 January 2013

\section{References}

1. Kawasaki N, Ohta M, Hyuga S, Hashimoto O, Hayakawa T: Analysis of carbohydrate heterogeneity in a glycoprotein using liquid chromatography/mass spectrometry and liquid chromatography with tandem mass spectrometry. Anal Biochem 1999, 269:297.

2. Krahmer MT, Johnson YA, Walters JJ, Fox KF, Fox A, Nagpal M: Electrospray quadrupole mass spectrometry analysis of model oligonucleotides and polymerase chain reaction products: determination of base substitutions, nucleotide additions/deletions, and chemical modifications. Anal Chem 1999, 71:2893.

3. Kapur A, Beck JL, Sheil MM: Observation of daunomycin and nogalamycin complexes with duplex dna using electrospray ionization mass spectrometry. Rapid Commun Mass Spectrom 1999, 13:2489.

4. Mo W, Sakamoto H, Nishikawa A, Kagi N, Langridge Jl, Shimonishi Y, Takao T: Structural characterization of chemically derivatized oligosaccharides by nanoflow electrospray ionization mass spectrometry. Anal Chem 1999, 71:4100.

5. Risberg A, Masoud H, Martin A, Richards JC, Moxon ER, Schweda EKH: Structural analysis of the lipopolysaccharide oligosaccharide epitopes expressed by a capsule-deficient strain of Haemophilus influenzae Rd. Eur J Biochem 1999, 261:171.

6. Lhoëst G, Zey T, Verbeeck RK, Wallemacq P, Maton N, DeHoux JP, Latinne D: Isolation from pig liver microsomes, identification by electrospray tandem mass spectrometry and in vitro immunosuppressive activity of a rapamycin tris-epoxide metabolite. J Mass Spectrom 1999, 34:28.

7. Castillo M, Alonso MC, Riu J, Barcelo D: Identification of polar, ionic, and highly water soluble organic pollutants in untreated industrial wastewaters. Environ Sci Technol 1999, 33:1300. 
8. Magnuson ML, Urbansky ET, Kelty CA: Determination of perchlorate at trace levels in drinking water by ion-pair extraction with electrospraymass spectrometry. Anal Chem 2000, 72:25.

9. Mauri D, Migliazza B, Pietta P: Liquid chromatography/electrospray mass spectrometry of bioactive terpenoids in Ginkgo biloba L. J Mass Spectrom 1999, 34:1361.

10. Putschew A, Jekel M: Induced in-source fragmentation for the selective detection of organic bound iodine by liquid chromatography/electrospray mass spectrometry. Rapid Commun Mass Spectrom 2003, 17:2279.

11. Huetteroth A, Putschew A, Jekel M: Selective detection of unknown organic bromine compounds and quantification potentiality by negative-ion electrospray ionization mass spectrometry with induced in-source fragmentation. Int J Environ Anal Chem 2007, 87:415.

12. Gil JH, Hong J, Choe JC, Kim YH: Analysis of fatty acyl groups of diacyl galactolipid molecular species by HPLC/ESI-MS with in-source fragmentation. Bull Korean Chem Soc 2003, 24:1163.

13. Tian Q, Duncan CJG, Schwartz SJ: Atmospheric pressure chemical ionization mass spectrometry and in-source fragmentation of lutein esters. J Mass Spectrom 2003, 38:990-995.

14. Carrier DJ, Eckers C, Wolff J-C: In-source" fragmentation of an isobaric impurity of lamotrigine for its measurement by liquid chromatography tandem mass spectrometry after pre-concentration using solid phase extraction. J Pharm Biomed Anal 2008, 47:731.

15. Yan Z, Caldwell GW, Jones WJ, Masucci JA: Cone voltage induced insource dissociation of glucuronides in electrospray and implications in biological analyses. Rapid Commun Mass Spectrom 2003, 17:1433.

16. Van Berkel GJ, Mcluckey SA, Glish GL: Electrospray ionization of porphyrins using a quadrupole ion trap for mass analysis. Anal Chem 1991, 63:1098.

17. Loo JA, Udseth HR, Smith RD: Collisional effects on the charge distribution of ions from large molecules, formed by electrosprayionization mass spectrometry. Rapid Commun Mass Spectrom 1988, 2:207.

18. Bure C, Gobert W, Lelievre D, Delmas A: In-source fragmentation of peptide aldehydes and acetals: influence of peptide length and charge state. J Mass Spectrom 2001, 36:1149.

19. Weinmann W, Stoertzel M, Vogt S, Wendt J: Tune compounds for electrospray ionisation/in-source collision-induced dissociation with mass spectral library searching. J Chromatogr A 2001, 926:199.

20. Zhang M-Y, Pace N, Kerns EH, Kleintop T, Kagan N, Sakuma T: Hybrid triple quadrupole-linear ion trap mass spectrometry in fragmentation mechanism studies: application to structure elucidation of buspirone and one of its metabolites. J Mass Spectrom 2005, 40:1017.

21. Hopfgartner G, Husser C, Zell M: Rapid screening and characterization of drug metabolites using a new quadrupole-linear ion trap mass spectrometer. J Mass Spectrom 2003, 38:138.

22. Abdel-Aal MT, El-Sayed WA, El-Ashry EH: Synthesis and antiviral evaluation of some sugar arylglycinoylhydrazones and their oxadiazoline derivatives. Arch Pharm Chem Life Sci 2006, 339:656.

23. Brouwer WG, Osika EM: Anti-viral aromatic hydrazones. In United States Patent number 5914351. 1999. Filed: 12 December 1997, Issued: 22 June 1999.

24. Abdel-Aziz HA, Abdel-Wahab BF, Badria FA: Stereoselective synthesis and antiviral activity of (1E,2Z,3E)-1-(Piperidin-1-yl)-1-(arylhydrazono)-2[(benzoyl/benzothiazol-2-oyl)hydrazono]-4-(aryl1)but-3-enes. Arch Pharm Chem Life Sci 2010, 343:152.

25. Abdel-Aziz HA, Mekawey AAl: Stereoselective synthesis and antimicrobial activity of benzofuran-based (1E)-1-(piperidin-1-yl)-N2-arylamidrazones. Eur J Med Chem 2009, 44:4985.

26. Frohberg P, Kupfer C, Stenger P, Baumeister U, Nuhn P: Lipoxygenaseinhibitoren, 4. Mitt.: synthese und cyclisierungsreaktionen offenkettiger N1arylsubstituierter amidrazone (pages 505-516). Arch Pharm 1995, 328:505.

27. Debord J, N'Diaye P, Bollinger JC, Fikri K, Penicaut B, Robert JM, Robert PS, Le-Baut G: Cholinesterase inhibition by derivatives of 2-amino-4,6dimethylpyridine. J Enzyme Inhib Med Chem 1997, 12:13.

28. El Ashry ESH, Rashed NA, Shobier HS: Glycosidase inhibitors and their chemotherapeutic value, part 3. Pharmazie 2000, 55:403.

29. Robert JM, Rideau O, Piessard SR, Duflos M, Le-Baut G, Grimaud N, Juge M, Petit JY: Synthesis and anti-inflammatory activity of polyazaheterrocyclic derivatives of 6-amino-2,4-lutidine and their precursors. Arzneimittel-Forschung/Drug Research 1997, 47:635.

30. Mamolo MG, Falagiani V, Vio L, Banfi E: Synthesis and antimycobacterial activity of some $\mathrm{N}^{1}$-[1-[3-aryl-1-(pyridin-2-, 3-, or 4-yl)-3-oxo]propyl]2-pyridinecarboxamidrazones. IL Farmaco 1999, 54:761.
31. Ranft D, Lehwark-Yvetot $G$, Schaper K, Buge A: $N^{1}$-hetaryl substituted pyridine- and pyrazinecarboxamidrazones with antimycobacterial activity. Arch Pharm 1997, 330:169.

32. Ranft D, Seyfarth T, Schaper K, Lehwark-Yvetot G, Bruhn C, Buge A: New $\mathrm{N}^{1}$-hetarylmethylene-substituted amidrazones with potential antimycobacterial activity. Arch Pharm 1999, 332:427.

33. Davies EP, Pittam JD, Mallion KB, Taylor NP: Process for preparing an antifungal azole with hydrazino and amidrazone intermediates. In United States Patent number 5861516. 1999. Filed: 9 April, 1997, Issued: 19 January 1999.

34. Drutkowski G, Donner C, Schulze I, Frohberg P: Derivatives of arylhydrazonic acids. Part 2: a facile approach to novel 4,5-dihydro-1 $\mathrm{H}$ 1,2,4-triazoles via cyclization of amidrazones. Tetrahedron 2002, 58:5317.

35. Frohberg P, Wagner C, Meier R, Sippl W: Derivatives of arylhydrazonic acids. Part 3: stereochemical rearrangement of Z-oxanilo-N1-dialkyl-N2arylamidrazones. Tetrahedron 2006, 62:6050.

36. Modzelewska-Banachiewicz B, Matysiak J, Niewiadomy A: Synthesis and mycological activity of the compounds obtained in the reaction of $\mathrm{N}^{3}$ substituted amidrazones with sulphinyl-bis-2,4-dihydroxybenzenethioyl. Eur J Med Chem 2001, 36:75.

37. Cocco MT, Congiu C, Lilliu V, Onnis V: Amidrazones as precursors of biologically active compounds - synthesis of diaminopyrazoles for evaluation of anticancer activity. Arch Pharm 2006, 339:7-13.

38. El Kaim L, Grimaud L, Jana NK, Mettetal F, Tirla C: Amines addition to alpha-nitrohydrazones: application to amidrazones and triazoles formation. Tetrahedron Lett 2002, 43:8925.

doi:10.1186/1752-153X-7-16

Cite this article as: Abdelhameed et al:: Induced in-source fragmentation pattern of certain novel $(1 Z, 2 E)-N$-(aryl)propanehydrazonoyl chlorides by electrospray mass spectrometry (ESI-MS/MS). Chemistry Central Journal 2013 7:16.

Publish with ChemistryCentral and every
scientist can read your work free of charge
"Open access provides opportunities to our
colleagues in other parts of the globe, by allowing
anyone to view the content free of charge."
W. Jeffery Hurst, The Hershey Company.
- available free of charge to the entire scientific community
- peer reviewed and published immediately upon acceptance
- cited in PubMed and archived on PubMed Central
- yours - you keep the copyright
submit your manuscript here:
http://www.chemistrycentral.com/manuscript/

